\title{
Synthesis and Characterization of NPK Slow Release Fertilizer for Red Onion by Using Empty Fruit Bunch (EFB) Char
}

\author{
E R Finalis ${ }^{1}$ Arfiana $^{1}$ I Noor $^{1}$ S D S Murti ${ }^{1}$ H Suratno $^{1}$ \\ E Rosyadi ${ }^{1}$ H Saputra ${ }^{1}$ R Noda ${ }^{2}$
}

\begin{abstract}
${ }^{1}$ Center for Technology Energy Resources and Chemical Industry, BPPT, Energy Building 625, Puspiptek Area, Serpong, South Tangerang, Banten 15314, Indonesia

${ }^{2}$ Chemical and Environment Engineering, Graduate School of Engineering, Gunma University, 1-5-1, Tenjin-cho, Kiryu-shi, Gunma 376-8515, Japan

*Corresponding author. Email: sd.sumbogo@bppt.go.id
\end{abstract}

\begin{abstract}
Red onion (Allium cepa L.) is considered one of the most commonly used vegetables in the culinary arts in Indonesia. It has many benefits, one of them is contain antioxidants that promote good health. Conventional cultivation of red onion is depended on the implementation of inorganic fertilizers to improve the production and the usage of synthetic pesticides to keep plants from pests attack. In this research, we was produced the NPK slow release fertilizer that formulated for red onion. In the process of synthesized the NPK slow release fertilizer, some main materials used to comply the need of nitrogen $(\mathrm{N})$, phosphor $(\mathrm{P})$, and potassium $(\mathrm{K})$, were Urea, Diammonium Phosphate (DAP), and Potassium Chloride $(\mathrm{KCl})$. Beside those materials, we was also used zeolite as a matrix to increase the characteristic of fertilizer. In the process of making NPK slow release fertilizer, we can used char as a material. Char that produced from the gasification process of empty fruit bunch (EFB) called as EFB char. It is a potential material as a potassium source that can be used in the making of NPK fertilizer. In this research, we was synthesized NPK fertilizer using EFB char as a alternate source of potassium that substitute the potassium chloride which was generally used in making NPK fertilizer. The aim of this research was to formulate and synthesize the NPK fertilizer for red onion using EFB char as a potential source of potassium and then characterize the fertilizer (surface area, pore volume, and morphology test) to analyse the effect of utilization EFB char and adding some material as micronutrient such as $\mathrm{Mg}$ (MgSO4 fertilizer) and S (ZA fertilizer) to improve the growth of red onion plant.
\end{abstract}

Keywords: Allium cepa L, NPK Fertilizer, NPK Slow Release, Empty Fruit Bunch Char

\section{INTRODUCTION}

Red onion (Allium cepa L.) is considered one of the most commonly used vegetables in the culinary arts in Indonesia. It has many benefits, one of them is contain antioxidants that promote good health. Conventional cultivation of red onion is depended on the implementation of inorganic fertilizers to improve the production and the usage of synthetic pesticides to keep plants from pests attack [1].

In this research, we was produced the NPK slow release fertilizer that formulated for red onion. In the process of synthesized the NPK slow release fertilizer, some main materials used to comply the need of nitrogen $(\mathrm{N})$, phosphor $(\mathrm{P})$, and potassium $(\mathrm{K})$, were Urea, Diammonium Phosphate (DAP), and Potassium Chloride 
$(\mathrm{KCl})$. Beside those materials, we was also used zeolite as a matrix to increase the characteristic of fertilizer [2].

Beside containing some main components and zeolite, NPK slow release fertilizer may contain some micronutrients to support the growth of red onion plant. That micronutrients including sulphur and magnesium. In the making process of fertilizer, there are some important nutrient that added such as nitrogen, phosphorus, zinc and sulphur. Sulphur is used to synthesize proteins, oils, chlorophyll, amino acids, vitamins and flavoured compounds in plants [3]. Sulphur is one of the molecular building blocks for a number of proteins, hormones and vitamins. In the form of sulphate, sulphur fulfils an important role in the water equilibrium in the plant, as well as in the soil. A sulphur deficient plant will experience yellowing or pale green colouring throughout the plant. Overall plant development and growth will be stunted without enough sulphur in the soil. Lack of sulphur is becoming widespread due to continuous use of sulphur free fertilizers. High sulphur requiring crops along with the restricted or no use of organic manures have accrued in depletion of the soil sulphur reserve. Magnesium has a number of key functions in plants. Particular metabolic processes and reactions were influenced by $\mathrm{Mg}$. Many essential plant functions require adequate $\mathrm{Mg}$ supplies, the most visible being its role in root formation, chlorophyll, and photosynthesis. Many less visible reactions are also dependent on an adequate supply of $\mathrm{Mg}$ [3].

In the process of making NPK slow release fertilizer, we can used char as a material. Char that produced from the gasification process of empty fruit bunch (EFB) called as EFB char. It is a potential material as a potassium source that can be used in the making of NPK fertilizer. [2].

Indonesia becomes the highest worldwide crude palm oil (CPO) production in the world. During this process, it also produce the waste such as mesocarp fiber, shell, EFB, trunk, and palm oil mill effluent (POME) [4]. EFB provides potency which can be used as a potassium source in the process of making NPK fertilizer. The utilization of EFB was not still optimized yet to be developed. From the study about the composition of EFB char that was done by Sari et al. [5] indicated that EFB char can be utilized as potassium source because of its high concentration contain. So in this research, we was synthesized NPK fertilizer using EFB char as a alternate source of potassium that substitute the potassium chloride which was generally used in making NPK fertilizer. The purpose of utilization of EFB char because of its characteristic such as porous structure and a relatively large surface area which was important in loading of fertilizer materials and minimize the fertilizer loss to increase soil fertility [1].

In the term of environmental issue, utilization of char to produce bio char-based fertilizer has been receiving increasing attention [6]. This bio char controlled the release of materials in soil because of its characteristic made a slow-release effect [7-10].
Therefore, we are absolutely sure bio char can be used as a fertilizer carrier to delay the release of nutrients into the soil, reduce fertilizer nutrient loss to leaching, and improve the utilization rate of fertilizer nutrients [11-12]. The aim of this research was to formulate and synthesize the NPK fertilizer for red onion using EFB char as a potential source of potassium and then characterize the fertilizer to analyse the effect of utilization EFB char and adding some material as micronutrient such as $\mathrm{Mg}$ (MgSO4 fertilizer) and S (ZA fertilizer) to improve the growth of red onion plant

\section{EXPERIMENTAL}

\subsection{Materials}

In this study, we used Urea for nitrogen source, Diammonium phosphate (DAP) for phosphate source, EFB Char and Potassium Chloride $(\mathrm{KCl})$ for potassium source, Mollases as binding agent, Zeolite as matrix, some micronutrient such as Magnesium from $\mathrm{MgSO}_{4}$ fertilizer and Sulphur from ZA fertilizer. EFB was obtained from Puspiptek area in Serpong, and char was produced from gasification of EFB. While for Zeolite was obtained from Sukabumi, West Java and others raw materials from local market in Serpong [2].

\subsection{Methods}

The NPK char fertilizer is made specifically for red onion with a formula containing $15 \%$ nitrogen, $10 \%$ phosphate, $11 \%$ potassium, 3\% Magnesium, and 5\% Sulphur (NPK Mg S 15-10-11-3-5). The materials were prepared according to the formulation for red onion plant. The raw materials: $145.91 \mathrm{~g}$ urea; $217.39 \mathrm{~g}$ DAP; 242.83 $\mathrm{g}$ EFB char; $35.29 \mathrm{~g} \mathrm{MgSO}_{4}$ and $208.33 \mathrm{~g} \mathrm{ZA}$ fertilizer were crushed and sieved to obtain particles powder form. After that, the mixing and granulation process were carried out. In order to support the granulation process, the molasses was sprayed to help bind the particles of raw materials and form granules. That process then followed by the drying of granules fertilizer, as showed in figure below.

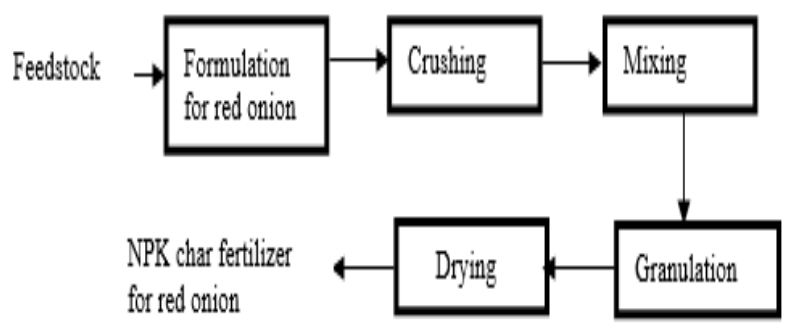

Figure 1 The Process for Making NPK Char Fertilizer

\subsection{Characterization of Fertilizer}

The NPK char fertilizer were characterized including surface area and pore volume, and also morphology test. 


\subsubsection{Brunauer - Emmett - Teller (BET) Test.}

BET test was conducted to study the surface area and pore volume of fertilizer. The samples were tested according to ISO 9277 - 10 standard. In this research we also tested the commercial NPK fertilizer to compare the result and analyse the effect of using EFB char in NPK char fertilizer.

\subsubsection{Morphology Test}

In order to observe the morphology and structure, the fertilizer samples were tested by using Scanning Electron Microscope (SEM) equipment, SEM JEOL JSM6510LA type. The morphology of the fertilizers were important to investigate the effect of EFB char application on the structure of the fertilizer product compared to morphology of commercial NPK fertilizer.

\section{RESULT AND DISCUSSION}

EFB was chopped into sizes of about $1 \mathrm{~cm}$ and put in the oven and put in the oven at a temperature of $100{ }^{\circ} \mathrm{C}$ for 2 hours in order to eliminate the moisture. After that, EFB entered the gasification reactor where the gasification process occured at temperature of $600{ }^{\circ} \mathrm{C}$. The comparison of dried EFB and char resulted could be seen in the following figure.

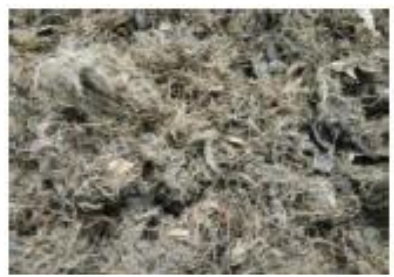

(a)

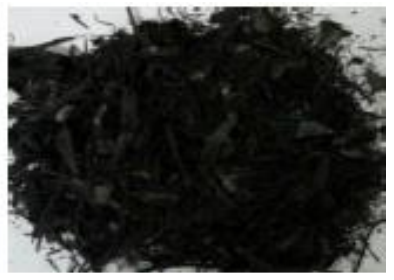

(b)
Figure 2 (a) Dried EFB, (b) Char from EFB

NPK char fertilizer was produced by using the raw composition stated in method and according to the process in the figure 1 . The granulation stage was carried out to produce a fertilizer product in the form of a granule with a size of about $3-5 \mathrm{~mm}$ and followed by the drying process at $60-80^{\circ} \mathrm{C}$ within 1 hour. This step was salient to produce dried granule fertilizer and prevent product damage due to its hygroscopic characteristic. The commercial NPK compared and product of NPK char fertilizer was shown in the figure 3. The physical appearance of the two fertilizers is very different where commercial NPK is pink while NPK char tends to be black due to the use of char as one of the raw materials. The high carbon content in the char causes the material to be difficult to stick during the granulation process so that it affects the form of the NPK char fertilizer produced. Thus the form of NPK char fertilizer produced is less round than the commercial NPK fertilizer.

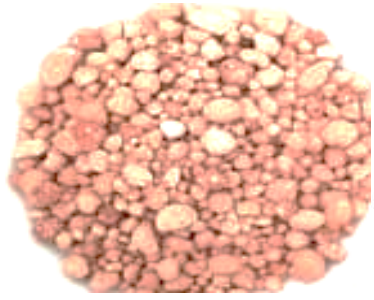

(a)

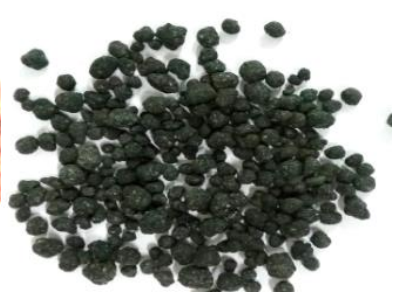

(b)
Figure 3 (a) Commercial NPK, (b) NPK Char

\subsection{Morphology Test}

A surface morphology study was performed on the NPK char fertilizer for red onion to observe the effects of EFB char utilization in NPK fertilizer for red onion. SEM analysis was performed to observe structural changes in NPK fertilizer. SEM images of NPK fertilizer for red onion were shown in Figure 3. All of the images were magnified 3000 times. Figure 4 (a) is SEM image for commercial NPK fertilizer and 4 (b) is SEM image for NPK char fertilizer. In figure 4 (a) it can be observed that morphological structure of commercial NPK fertilizer was more dense compared with figure 4 (b). In figure 4 (b), morphological structure of NPK char fertilizer is more porous. It means that the utilization of EFB char make the fertilizer more porous. According to the reference [13], as we can see in figure 5, EFB char has the porous structure and with an even distribution of pores. The pores form an elongated structure with the smooth surface. This pores structure was formed as a result of the gasification or pyrolysis process at high temperature [13].

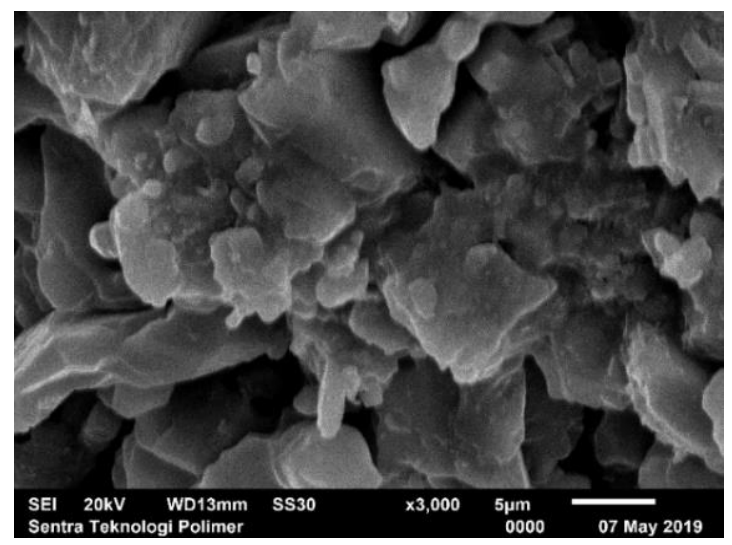

Figure 4a SEM images of Commercial NPK Fertilizer 


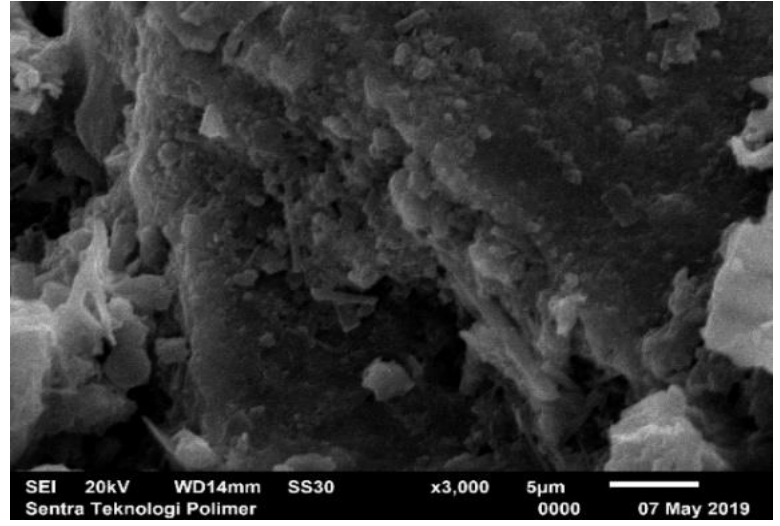

Figure 4b SEM images of Commercial NPK Fertilizer

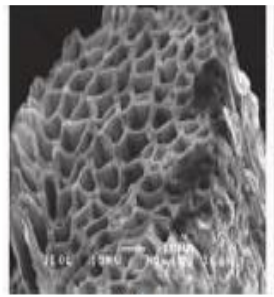

(a) $\mathrm{T}=350{ }^{\circ} \mathrm{C}$

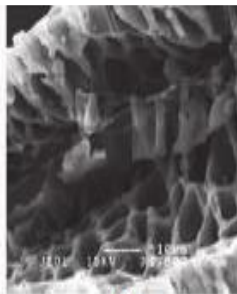

(b) $\mathrm{T}=500{ }^{0} \mathrm{C}$
Figure 5 The Morphology of EFB Char at Any Different Gasification Temperature

The other phenomenon that was seen in figure $4(\mathrm{~b})$ is the morphological surface structure of NPK char fertilizer has a fairly rough surface due to the attachment of micronutrient materials on the surface of fertilizer. According to [14], that phenomenon also showed that the micronutrient materials were firmly stick to the char.

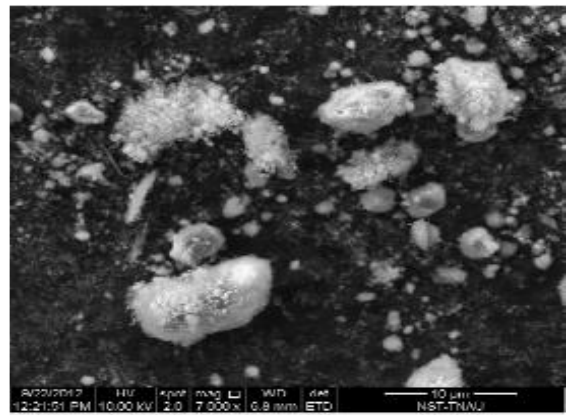

Figure 6. SEM Image of Sulphate Loaded Surface Modified Nano Zeolite Fertilizer

The adding of micronutrients in fertilizer formulation caused the surface morphological changes. Thirunavukkarasu and Subramanian in 2014 [15] had observed nano zeolite with surface modification that was used for carrier in order to produce nano zeolite based nano sulphur fertilizer. The SEM results showed in figure 6along with the result of our research (figure 4 (b)), indicated some deposit of micronutrients that contain of sulphate.
Table 1. BET Test of NPK Char Red onion vs Phonska

\begin{tabular}{|c|c|l|c|l|}
\hline \multirow{2}{*}{ Properties } & \multicolumn{2}{|c|}{ NPK Char } & \multicolumn{2}{c|}{ NPK Phonska } \\
\cline { 2 - 3 } & \multicolumn{2}{|c|}{ Red Onion } & \multicolumn{2}{c|}{} \\
\hline Surface Area & 2.37 & $\mathrm{~m}^{2} / \mathrm{g}$ & 0.2869 & $\mathrm{~m}^{2} / \mathrm{g}$ \\
\hline Pore Volume & 0.007669 & $\mathrm{cc} / \mathrm{g}$ & 0.0000494 & $\mathrm{cc} / \mathrm{g}$ \\
\hline
\end{tabular}

The BET test was carried out on 2 different types of fertilizers : NPK char for red onion and commercial NPK fertilizer (phonska). The results of BET test are given in table 1 . From the results of the BET test, the value of the surface area of NPK fertilizer for red onion is higher about 8 times compared to commercial fertilizer (phonska). This is because the use of the EFB gasification char which has porous structure as shown by the SEM test results in figure 4 (b). This is in line with the pore volume value for NPK char fertilizer which also points to a higher value of $0.007669 \mathrm{cc} / \mathrm{g}$. At higher bed temperatures during gasification process, pore surface area developed inside the char particle due to the removal of volatile matter in the material which then increasing the pores volume [16] as well as surface area. Moreover, that will also give good effect to the fertilizer [2] which is support the red onion growth where the well-developed pore structure and the high surface area of NPK char particles increased the adsorption capacity of fertilizer [17] as shown in table 1, so that NPK char fertilizers indicated the slow-release effect of nutrients in soil.

\section{CONCLUSIONS}

The results of this research showed that NPK fertilizer for red onions can be synthesized using EFB char from gasification. The utilization of EFB char made the fertilizer more dense and porous than commercial fertilizers. The addition of micronutrients in fertilizer formulation caused the surface morphological changes. From the results of the BET test, the value of the surface area and pore volume of NPK fertilizer is higher than commercial fertilizers.

\section{ACKNOWLEDGMENT}

The authors would like to thank The Agency of Assessment and Application of Technology and Japan Government for the financial support. This project could be achieved through the SATREPS program which is a collaboration of the two parties above.

\section{REFERENCES}

[1] R R Rukmowati Brotodjojo and D Arbiwati 2017 Int'l Journal of Advances in Agricultural \&Environmental Engg4 89.

[2] Arfiana, E R.Finalis, Fausiah, I Noor, E F Destian, D B I Nuswantoro, S D S Murti, H Saputra, R Noda 2019 AIP Conference Proceeding 2097 doi.org/10.1063/1.5098226. 
[3] R Sakal and A P Singh 1997 Proceeding of The Suphur Institute (TSI) /Fertiliser Association of India (FAI) / International Fertiliser Industry Association (IFA) Symposium on Sulphur in Balanced Fertilisation pp. SI-2 / 1-6.

[4] Y S Pradana and A Budiman 2015 Journal of engineering Science and Technology, Special Issue on SOMCHE 2014 and RSCE 2014 Conference 1-8.

[5] N A Sari, C F Ishak, and R A Bakar 2014 American Journal of Agricultural and Biological Science9 (3) pp.450 - 456.

[6] Chen P, Sun M X, Zhu Z.X, Zhang J D, Shen G Q 2015 Anal. Bioanal. Chem407 6149-6157

[7] Khan M A, Kim K K, Wang M Z, Lim B K, Lee W H, Lee J Y 2008 Environmentalist 28 231-235.

[8] Lee J W, Hawkins B, Li X N, Day D M 2013 Biochar fertilizer for soil amendment and carbon sequestration. In Advanced Biofuels and Bioproducts Springer 57-68.

[9] Hagemann N, Kammann C I, Schmidt H P, Kappler A, Behrens S 2017 Nitrate capture and slow release in biochar amended compost and soil. PLoS ONE 12 e0171214.
[10] Day D, Evans R J, Lee J W, Reicosky D 2004 Prepr. Pap. Am. Chem. Soc. Div. Fuel Chem200449 352-355.

[11] Zhong X M, Y N Zhu, J Liu and A G Qin $2006 \mathrm{~J}$. Agro-Environ. Sci25 154-157

[12] Magrinibair K A, S Czernik, H M Pilath, R J Evans, P C Maness and J Leventhal 2009 Ann. Environ. Sci 3 217-225

[13] N Claoston, A W Samsuri, M H A Husni, and M S M Amran 2014 Waste Management \& Research, 32 (4), pp. 331 - 339.

[14] L Chen, Q C Chen, P H Rao, L Yan, A Shakib, and G Q Shen 2014 Sustainability10 2740 DOI: $10.3390 /$ su 10082740 .

[15] M Thirunavukkarasu and K S Subramanian 2014 Journal of Applied and Natural Science 6 (1) 1926

[16] M Ahmad, S S Lee, X M Dou, D Mohan, J K Sung, J E Yang, and Y S Ok 2012 Biosource Technology 118, pp. 536 - 544.

[17] Agegnehu G , A M Bass, P N Nelson, B Muirhead, G Wright and M I Bird 2015Agric. Ecosyst.Environ. 213 72-85. 